Supporting Information for

\title{
Post Modification of Polybutadienes by Photoinduced Hydrogen Abstraction from Benzoxazines and Their Thermally Activated Curing
}

\author{
Mustafa Arslan ${ }^{1}$, Baris Kiskan ${ }^{1, *}$, Yusuf Yagci ${ }^{1, *}$ \\ Istanbul Technical University, Department of Chemistry, Maslak, 34469, Istanbul, Turkey
}

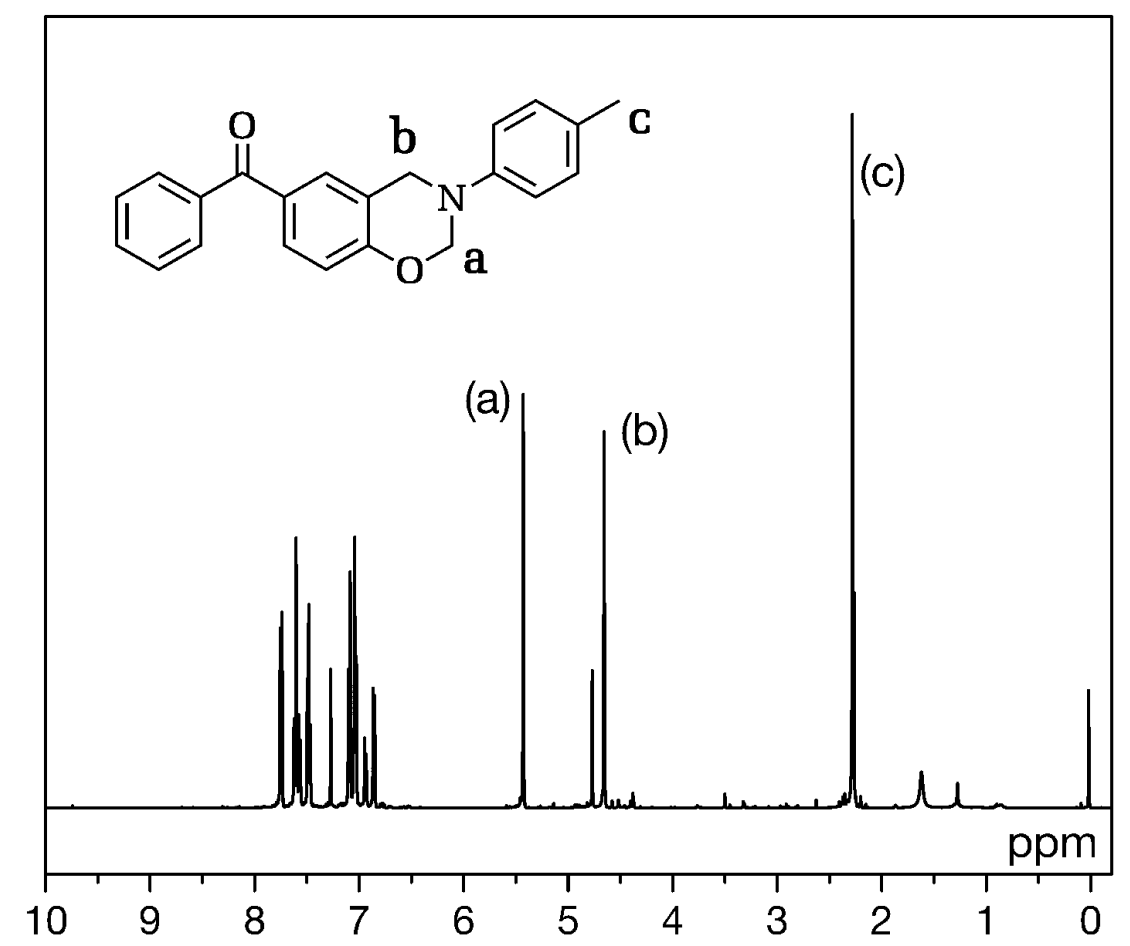

Figure S1. ${ }^{1} \mathrm{H}$ NMR spectrum of BPh-ptol 


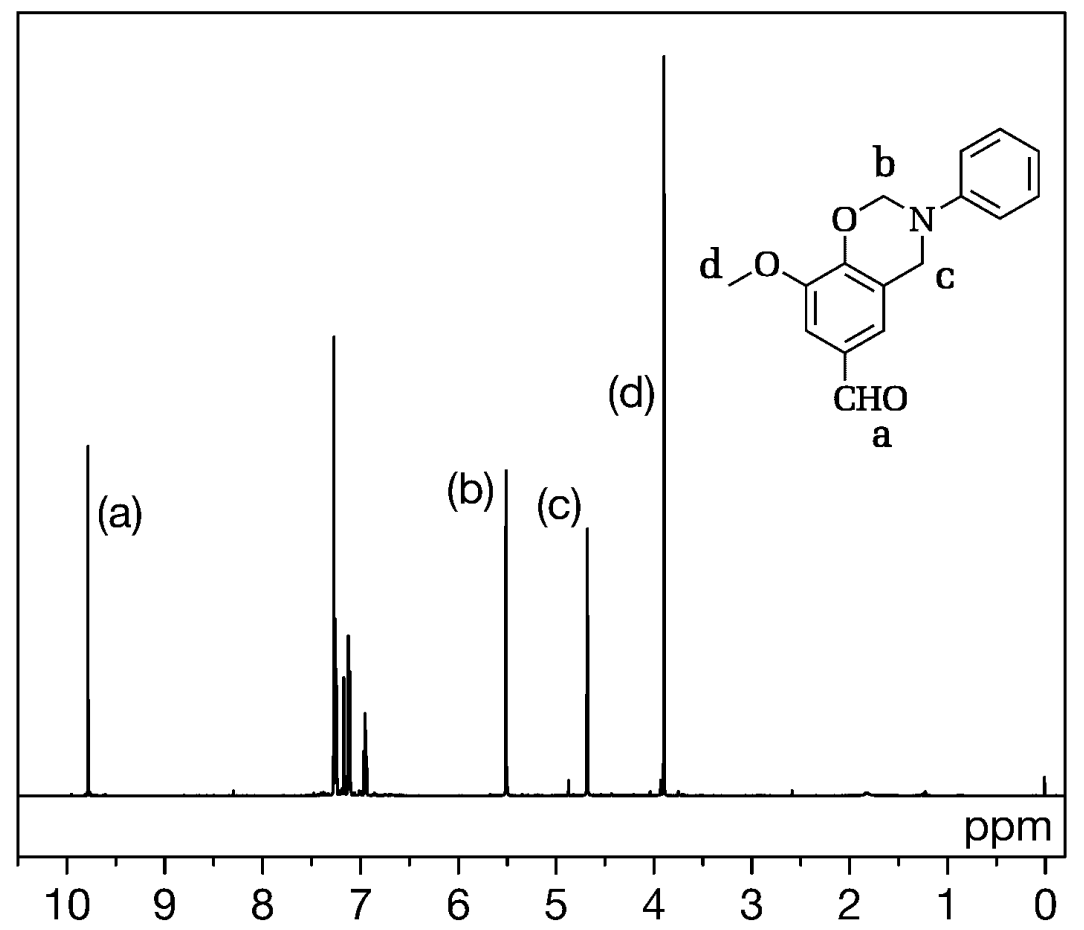

Figure S2. ${ }^{1} \mathrm{H}$ NMR spectrum of Van-a

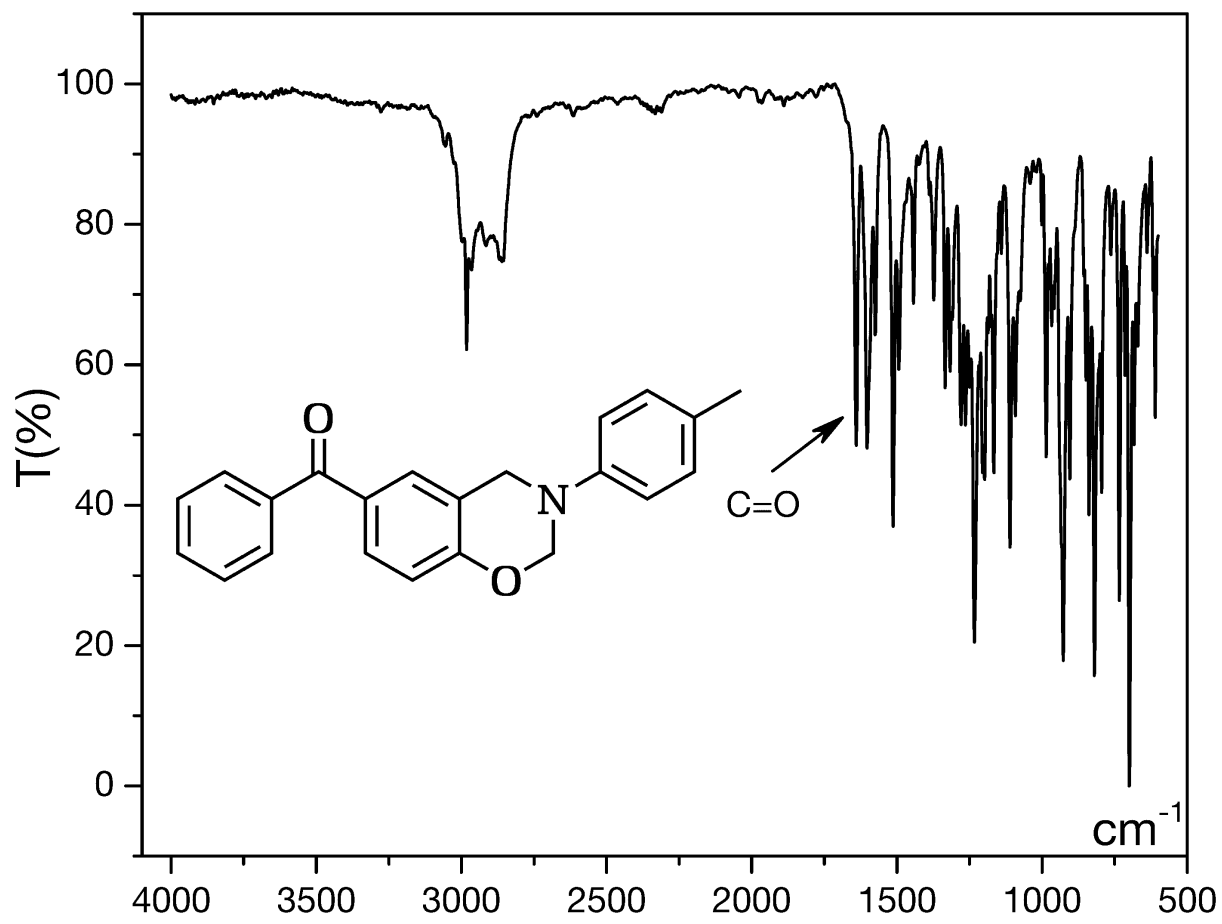

Figure S3. FT-IR spectrum of BPh-ptol 


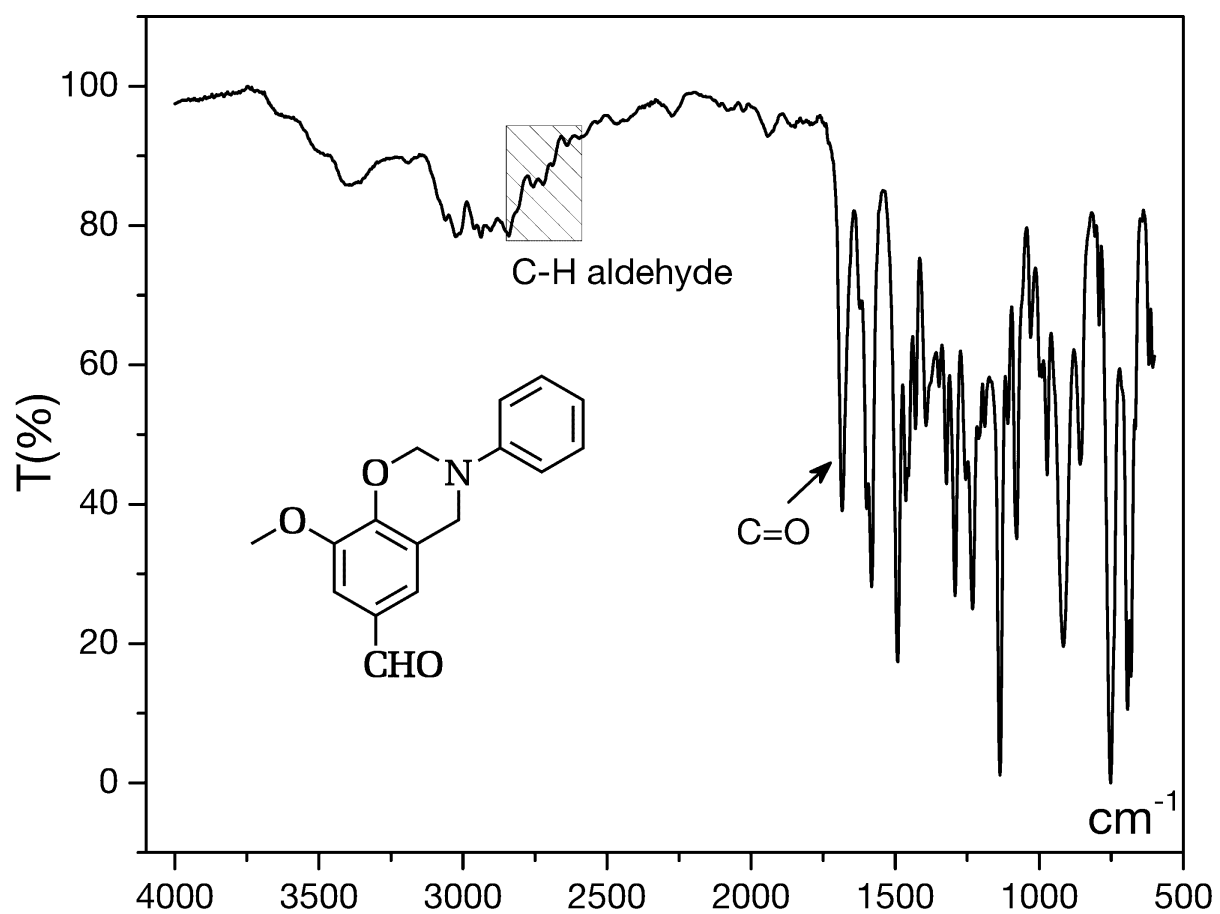

Figure S4. FT-IR spectrum of Van-a

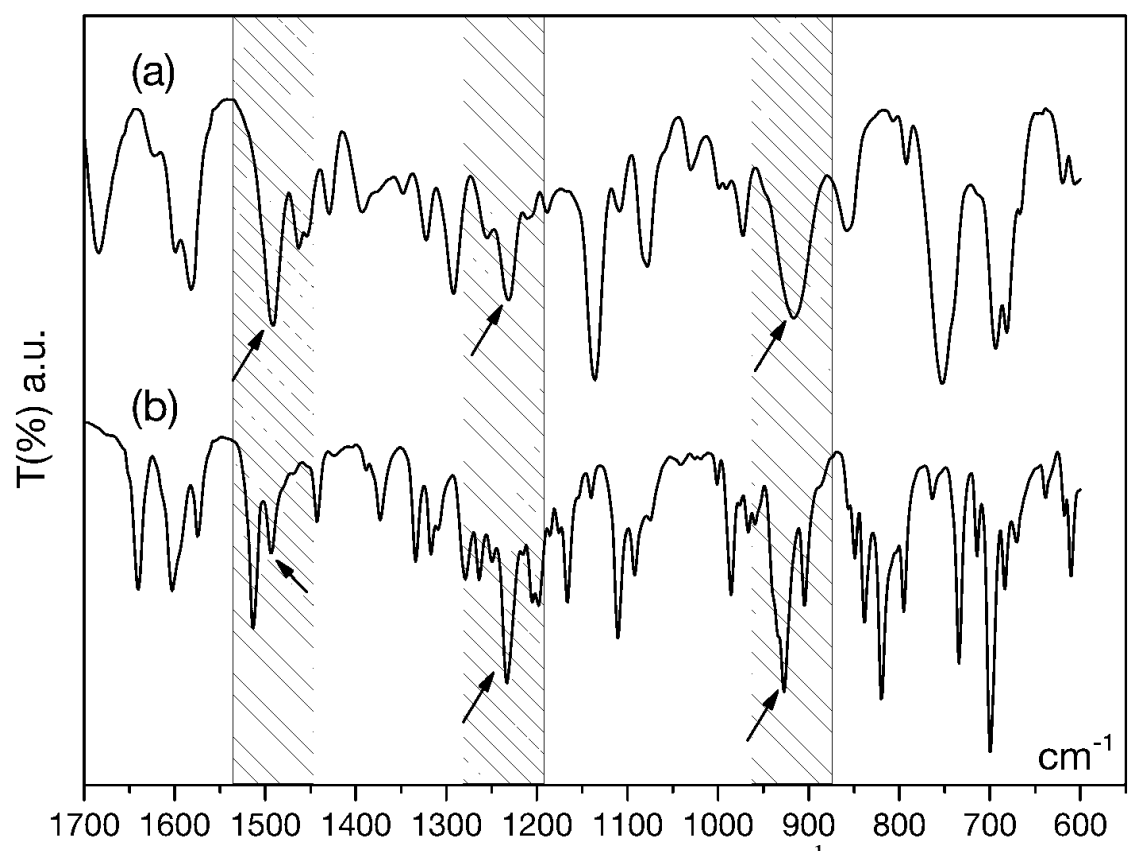

Figure S5. Overlaid FT-IR spectra for region below $1700 \mathrm{~cm}^{-1}$ of Van-a (a) and BPh-ptol (b) 


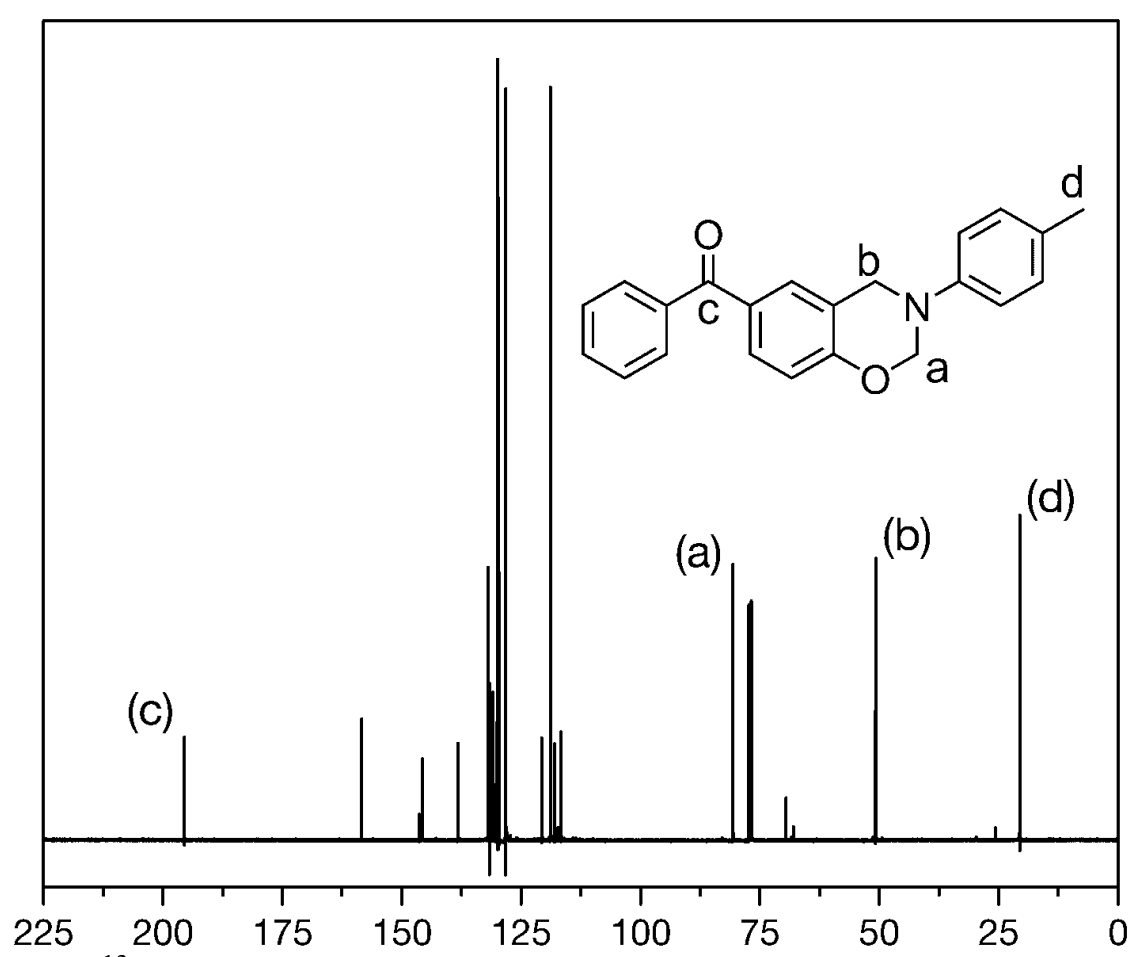

Figure S6. ${ }^{13} \mathrm{C}$ NMR spectrum of $\mathrm{BPh}-$ ptol

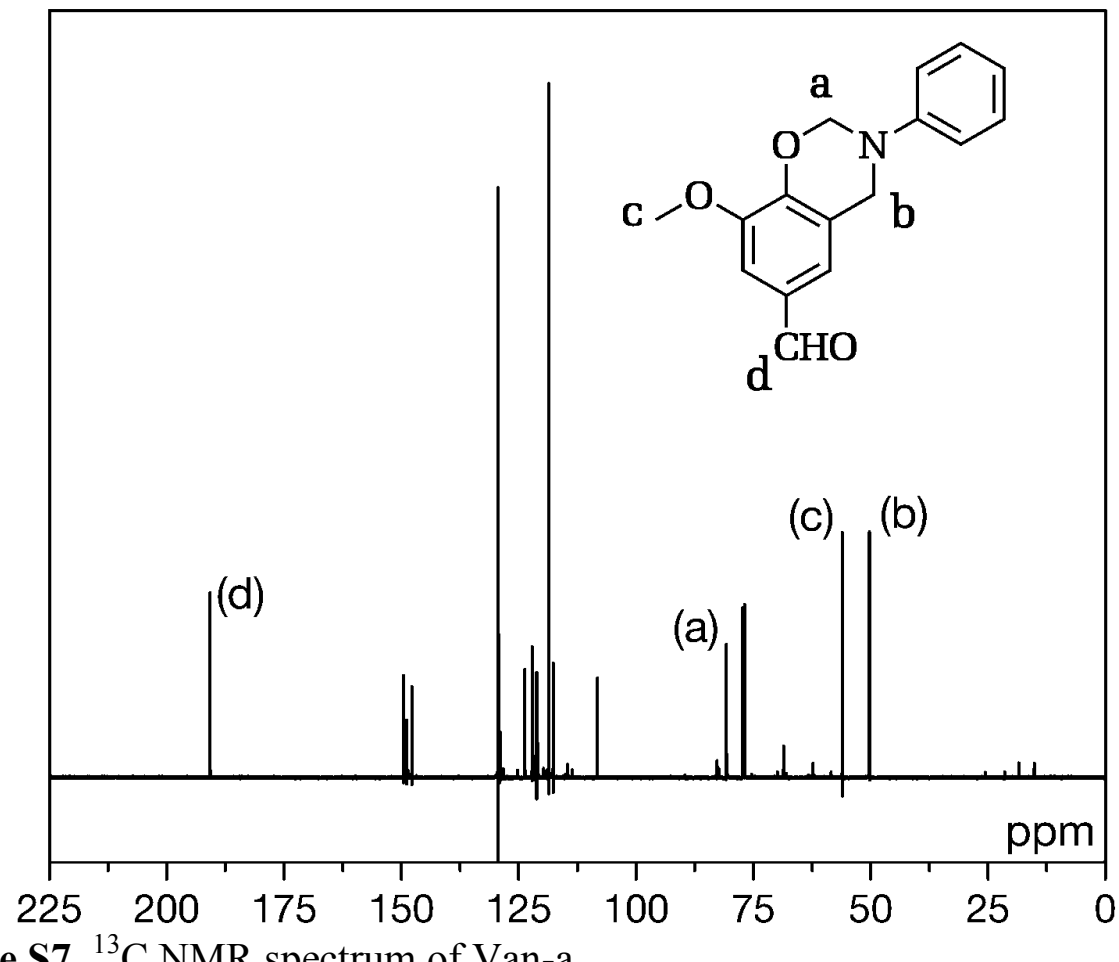

Figure S7. ${ }^{13} \mathrm{C}$ NMR spectrum of Van-a 


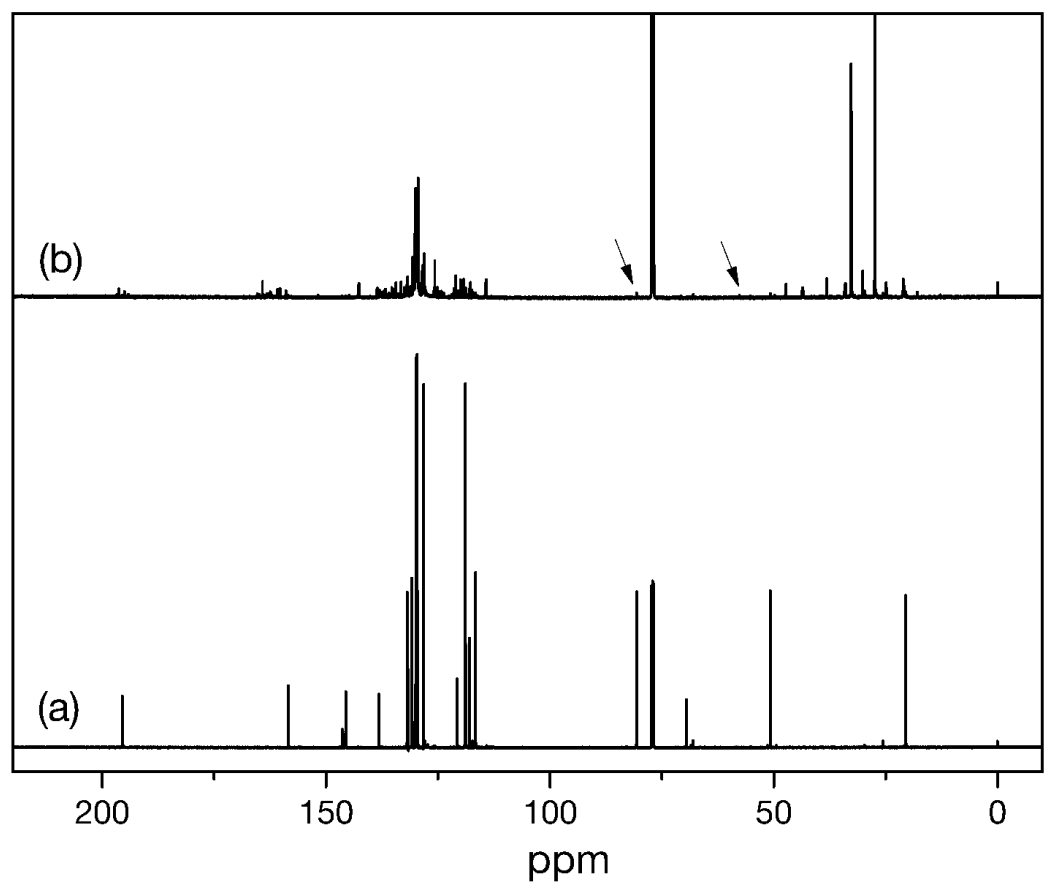

Figure S8. ${ }^{13} \mathrm{C}$ NMR spectra of BPh-ptol (a), and poly(butadiene-co-BPh-ptol)

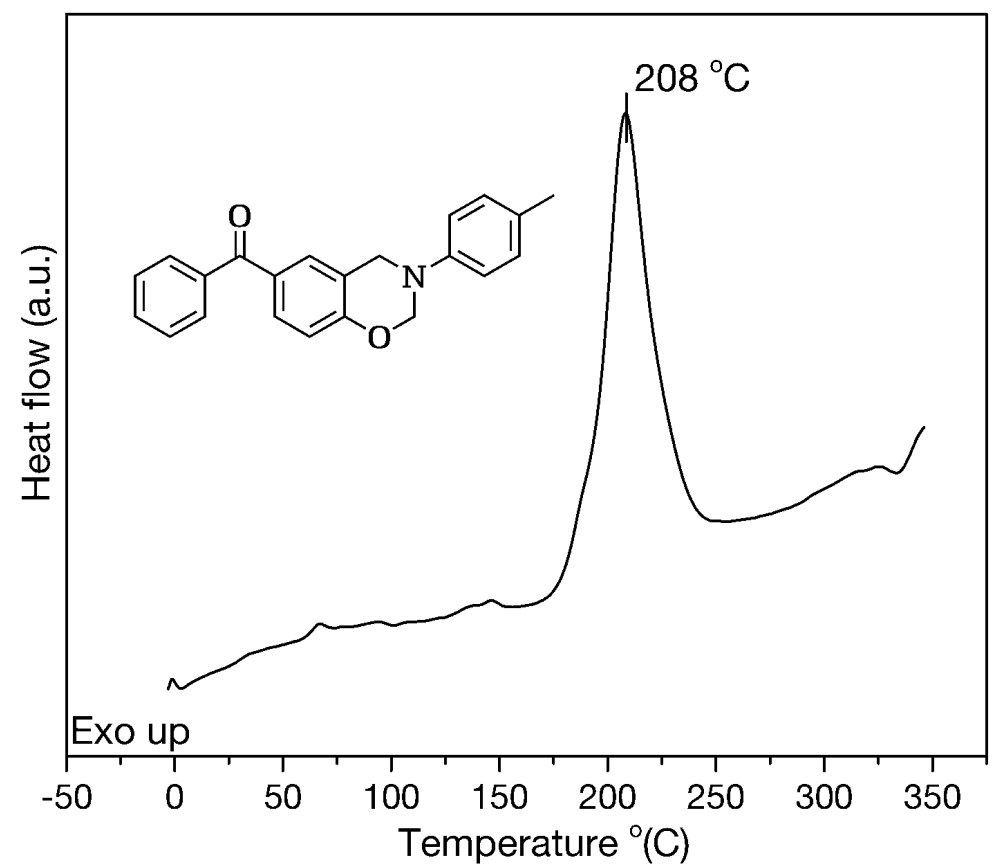

Figure S9. DSC thermograph of BPh-ptol monomer 


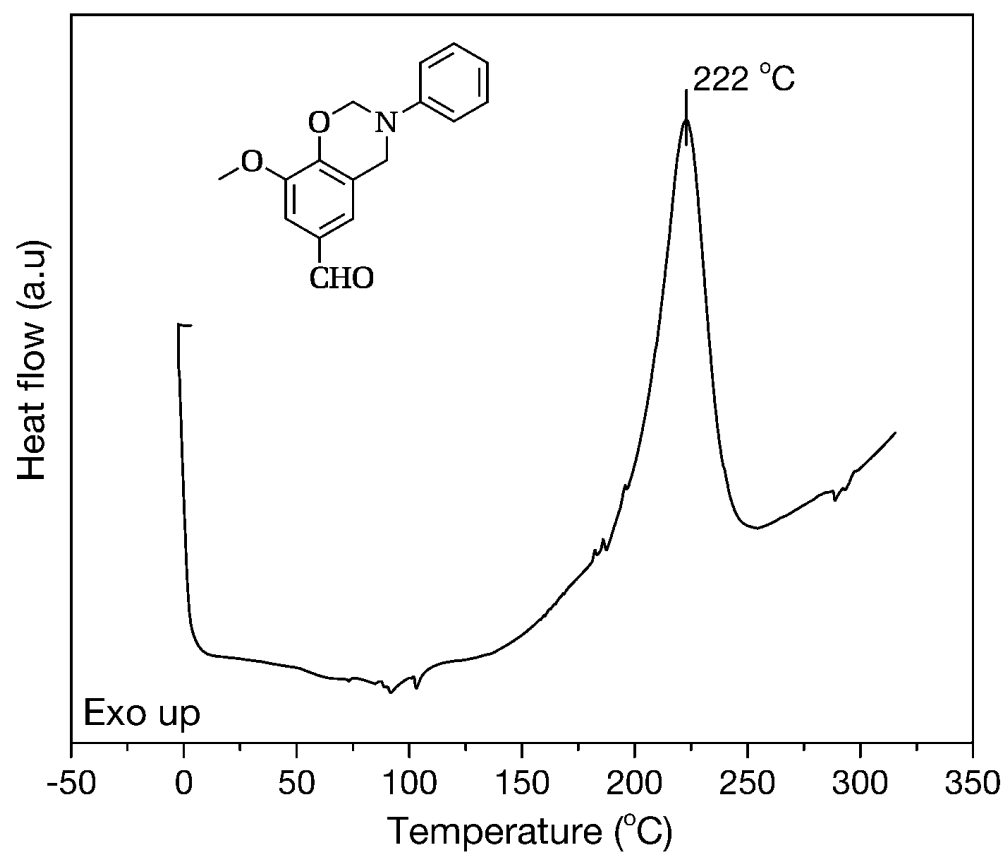

Figure S10. DSC thermograph of Van-a monomer

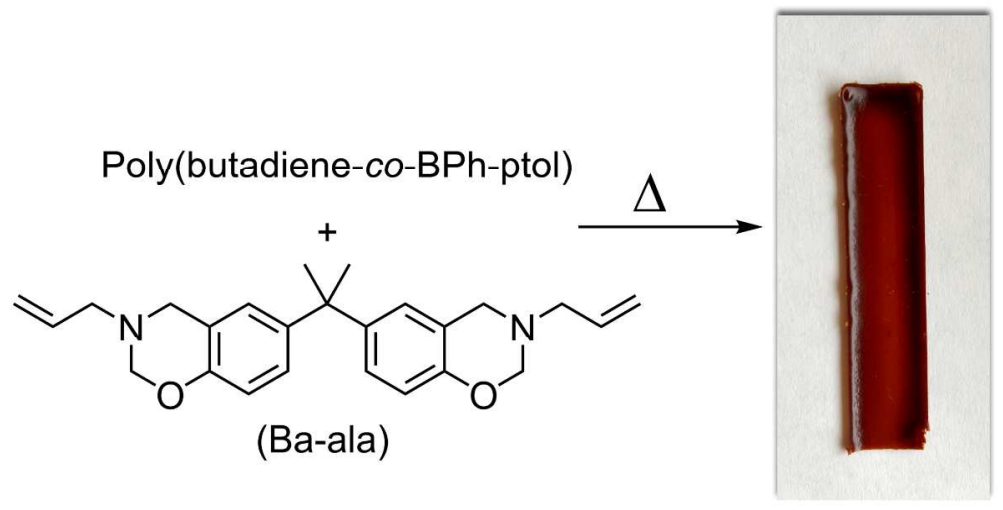

Figure S11. Image of cured film of poly(butadiene-co-BPh-ptol) and allyl benzoxazine (Baala) 